\title{
Transforaminal epidural steroid injection combined with radio frequency for the treatment of lumbar disc herniation: a 2-year follow-up
}

Wen-Bo Wei ${ }^{1,2,3}$, Sha-Jie Dang ${ }^{1,2,4}$, Ling Wei ${ }^{5}$, Tian Liu ${ }^{1,2^{*}}$ and Jue Wang ${ }^{1,2^{*}}$

\begin{abstract}
Background: To assess the therapeutic efficacy of transforaminal epidural steroid injection (TFESI) combined with radio frequency (RF) for the treatment of lumbar disc herniation (LDH).

Methods: A total of 230 patients participated in the study: TFESI (Group T, $n=110$ ), TFESI combined with RF (Group $T R, n=120)$. Visual analogue scale (VAS), Oswestry disability index (ODI) and Global perceived effect (GPE) scale were measured pre-operation, 1, 3, 6, 12 and 24 months after the operation. Hospitalization time, treatment time, complications, and recurrence were compared between the two groups.

Results: The VAS and ODI at each observation point of the post-operation were significantly decreased compared with the pre-operation in both groups $(P<0.05)$. There was no statistically difference of VAS and ODI between the two groups at 1 and 3 months of the post-operation $(P>0.05)$. However, The VAS and ODI scores in Group TR were significantly lower than that in Group T at 6, 12 and 24 months of the post-operation $(P<0.05)$. The GPE in group TR was high in the early days, while that at 1 and 3 months after treatment was significantly higher than that in group T $(P<0.05)$. The recurrence rate in Group TR was lower than that in Group T $(P=0.002)$. There was no significant difference in hospitalization time, complications, VAS and ODI score at the pre-operation between the two groups $(P>0.05)$.

Conclusion: These findings suggest that TFESI combined with RF could effectively improve the pain and function, and had a long-term satisfactory effect for the treatment of LDH.
\end{abstract}

Keywords: Transforaminal epidural steroid injection, Radio frequency, Lumbar disc herniation

\footnotetext{
* Correspondence: tianliu@xjtu.edu.cn; juewang_xjtu@126.com

${ }^{1}$ The Key Laboratory of Biomedical Information Engineering of Ministry of Education, The Key Laboratory of Neuro-informatics \& Rehabilitation Engineering of Ministry of Civil Affairs, and Institute of Health and Rehabilitation Science, School of Life Science and Technology, Xi'an Jiaotong University, Xi'an 710049, P. R. China

Full list of author information is available at the end of the article
}

C C The Author(s). 2021 Open Access This article is licensed under a Creative Commons Attribution 4.0 International License, which permits use, sharing, adaptation, distribution and reproduction in any medium or format, as long as you give appropriate credit to the original author(s) and the source, provide a link to the Creative Commons licence, and indicate if changes were made. The images or other third party material in this article are included in the article's Creative Commons licence, unless indicated otherwise in a credit line to the material. If material is not included in the article's Creative Commons licence and your intended use is not permitted by statutory regulation or exceeds the permitted use, you will need to obtain permission directly from the copyright holder. To view a copy of this licence, visit http://creativecommons.org/licenses/by/4.0/. The Creative Commons Public Domain Dedication waiver (http://creativecommons.org/publicdomain/zero/1.0/) applies to the data made available in this article, unless otherwise stated in a credit line to the data. 


\section{Background}

Lumbar radicular pain is caused by Lumbar disc herniation (LDH), which is a common orthopaedic disease characterized by low back pain and sciatica. The incidence rate is $10-20 \%$ [1] and has become a global health issue [2]. There are many treatment methods for LDH, including conservative treatment, interventional and surgery therapy. Clinically, patients with LDH who had no effect of conservative treatment undergo invasive treatment. Choosing an invasive therapy that has fewer traumas, maintains the integrity and stability of the spine, and reduces the incidence of postoperative complications has become the focus of LDH treatment.

Transforaminal epidural hormone injection (TFESI), as a minimally invasive interventional surgery, is widely used in the treatment of LDH [3]. It has the advantages of less trauma, fewer complications, and faster onset. It relieves symptoms by injecting corticosteroids and local anesthetics around the dural and nerve roots that cause radicular pain. Previous studies have shown that TFESI has a positive short-term effect in reducing lumbar back pain. However, the medium- and long-term treatment efficiency of TFESI is unsatisfactory [3, 4].

Radio frequency (RF) is one of the interventional therapies for $\mathrm{LDH}$, which uses radio frequency alternating current to ablate the tissue around the needle electrode [5]. Radio frequency can be used as a means that targets certain anatomical structures of interest, usually nerves. Some results show that the medium- and long-term treatment efficiency is satisfactory $[6,7]$.

We hypothesized that TFESI combined with RF could lead to a significant reduction in pain related to LDH for a long-term. The present study aimed to retrospectively analyze the 2-year follow-up data after TFESI combined with RF for the treatment of LDH in YangLing Demonstration Zone Hospital, and evaluate the effectiveness and safety through clinical assessment tools and patient interviews.

\section{Methods}

\section{Study design}

We retrospectively reviewed the medical records of 230 patients, who were treated at the Department of Pain Management, YangLing Demonstration Zone Hospital between January 2014 and December 2016. This study was approved by the clinical research ethics committee of YangLing Demonstration Zone Hospital (No. 2016-021). This study followed the Good Clinical Practice guidelines and the guidelines of the Helsinki Declaration. The study included 110 cases that received TFESI (Group T) and 120 cases that received TFESI combined with RF (Group TR).

\section{Patients}

Patients (aged $21 \sim 70$ years old, BMI $16 \sim 38$ and ASAI III) undergoing TFESI combined with RF or TFESI operation as LDH were screened in this study (Fig. 1). All patients presented who refused open surgery with lower back pain with sciatica and were ineffective after 3 months of adequately conservative treatment. The patient's signs and symptoms are caused by herniated discs, which was confirmed by MRI and CT. All patients were recorded CTF-classification of LDH [8]. The following patients were excluded: multi-segmental disc herniation, sequestration type disc herniation, cauda equina syndrome, lumbar spinal stenosis, spinal metastatic disease, lumbar spondylolisthesis, psychosis, uncorrectable bleeding quality, patients who lost to follow-up, and previous lumbar surgery.

\section{Procedures}

Guided by C-arm fluoroscopy, the patient is placed in the prone position with U-shaped pillows under the chest and both ilia so that the abdomen is suspended. The injection site was sterilized with antiseptic fluid and draped with surgical towels.

In the TFESI procedure, a local anesthetic $(3 \mathrm{~mL}$ of $0.5 \%$ lidocaine) is injected into the skin and subcutaneous tissue at the injection site. A 0.35 -in. $18 \mathrm{~cm}$ needle is advanced in the area below the pedicle. As the epidural space is approached, anteroposterior and lateral view will be taken to confirm the needle position. $0.5 \mathrm{~mL}$ contrast medium was used to check whether the needle was in the epidural space. $3 \mathrm{~mL}$ mixture of corticosteroids and anesthetics $(80 \mathrm{mg}$ methylprednisolone, $5 \mathrm{~mL} 2 \%$ lidocaine and $5 \mathrm{~mL} 1 \%$ ropivacaine) were injected (Fig. 2).

In the RF procedure, a puncture needle using a radio frequency probe is used to pierce the protrusion. According to the preoperative physical examination and imaging examination, the responsible target position of the intervertebral disc was determined. $6-14 \mathrm{~cm}$ was opened beside the posterior midline. The puncture was carried out through the safety triangle with an included angle of 20-40 at the coronal position to the herniated part of the intervertebral disc. After confirming the position of the guide needle with the anteroposterior and lateral view, we remove the probe, use or not $1 \mathrm{~mL}$ contrast medium to check whether the needle is in the disc, then advance the catheter rod through the guide needle to the center of the protruding portion. Radio frequency treatment was performed using a radio frequency temperature-controlled thermocouple (XJ-08; Xi'an Sterilization Equipment Manufacturing Co., Ltd.; Xi'an). The electrodes are inserted into a puncture needle, sensory and motor responses during RF neurotomy procedure might be used (albeit not obligatorily) to confirm the close proximity of targeted (and non-targeted) nerves to 


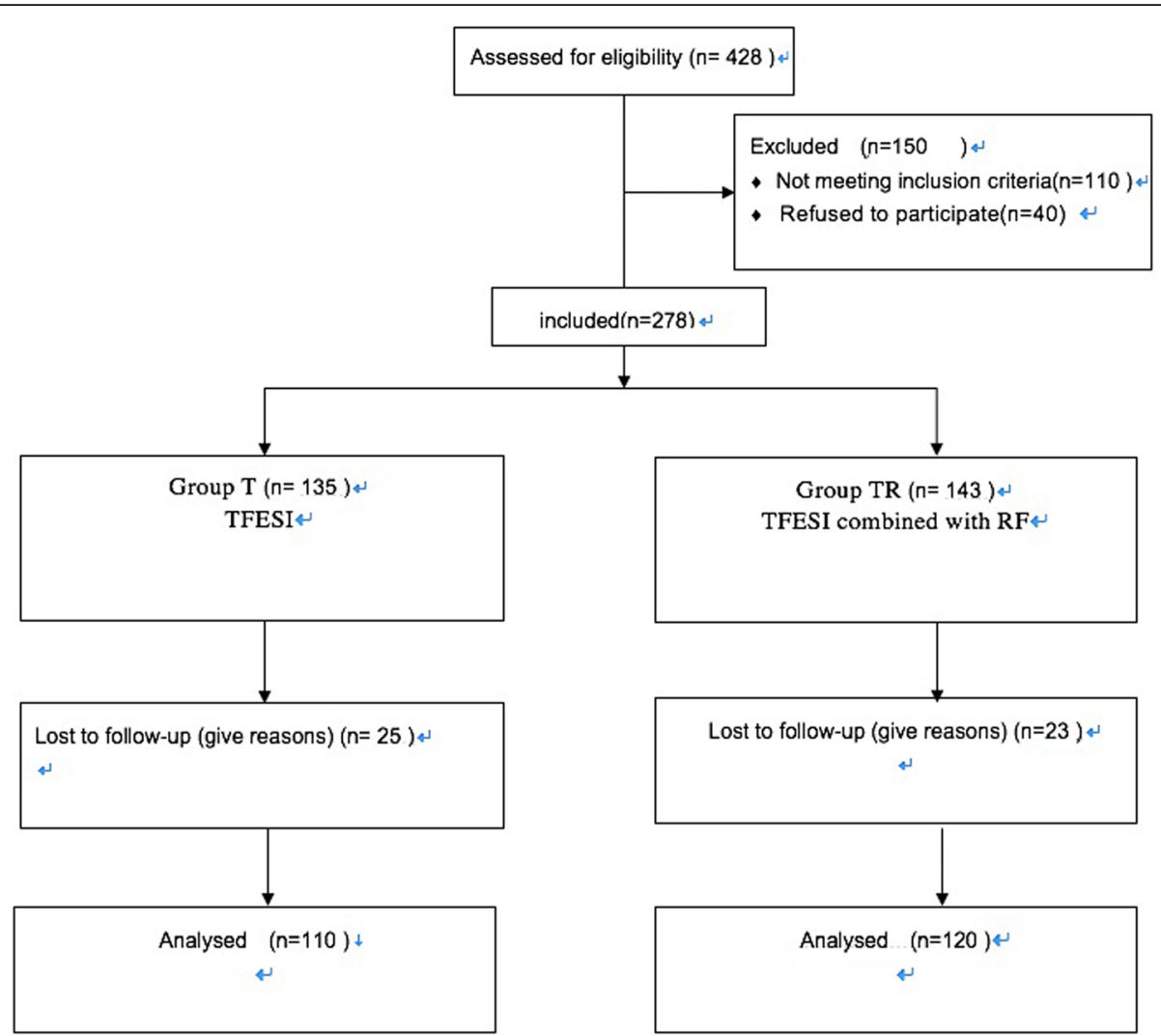

Fig. 1 Schematic illustration of the study design. Note: all 230 patients were included in the treatment. Abbreviations: TFESI, transforaminal epidural steroid injection; RF, radio frequency

RF electrodes. Thermo coagulation was applied at $60^{\circ} \mathrm{C}$, $70^{\circ} \mathrm{C}$, and $80^{\circ} \mathrm{Cfor} 60 \mathrm{~s}$ each, and $90^{\circ} \mathrm{C}$ for 100 s. (Fig. 3).

Sex, age, BMI, operating time, and hospitalization time were evaluated and recorded. Follow-ups were conducted preoperatively, and at $1,3,6,12$ and 24 months postoperatively. During the individual interviews, we collected information from the patients regarding side effects, discomfort, and recurrence. Assessments were conducted using the visual analog scale (VAS) [9], the Oswestry Disability Index (ODI) [10], andthe Global perceived effect (GPE) [11]. The VAS rates pain severity as a score from 0 to 10, 0 indicates no pain and a score of 10 indicates the most severe pain. The ODI assesses low back pain-related disability: the higher the score, the

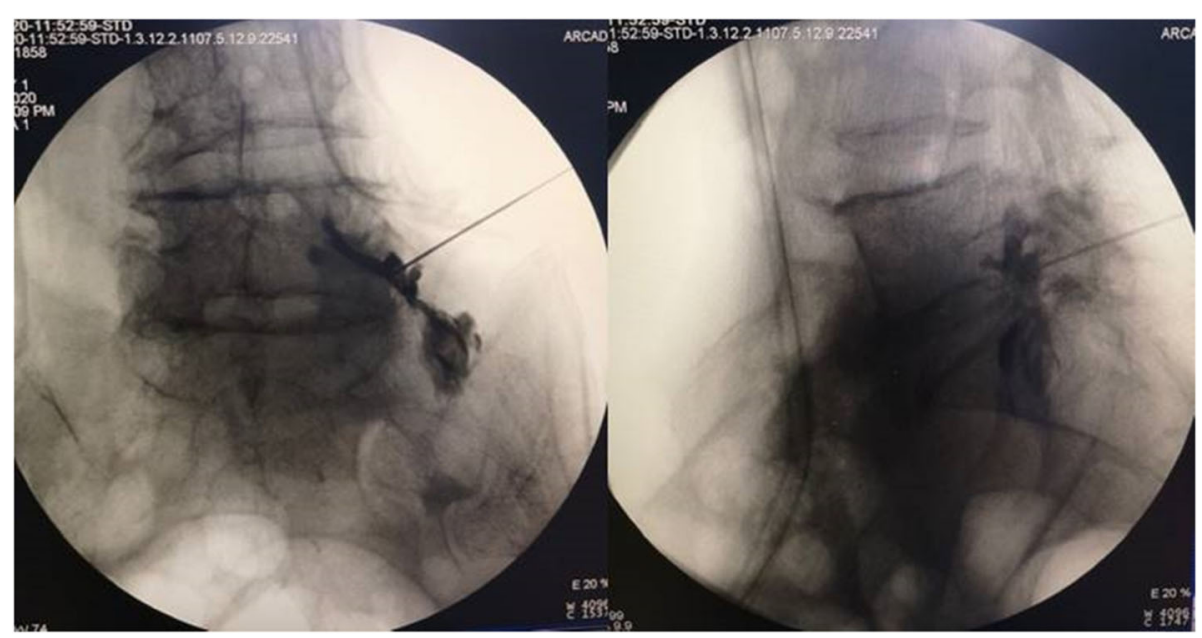

Fig. 2 Anteroposterior and lateral C-arm images with needle placement and spread of dye along the nerve root 


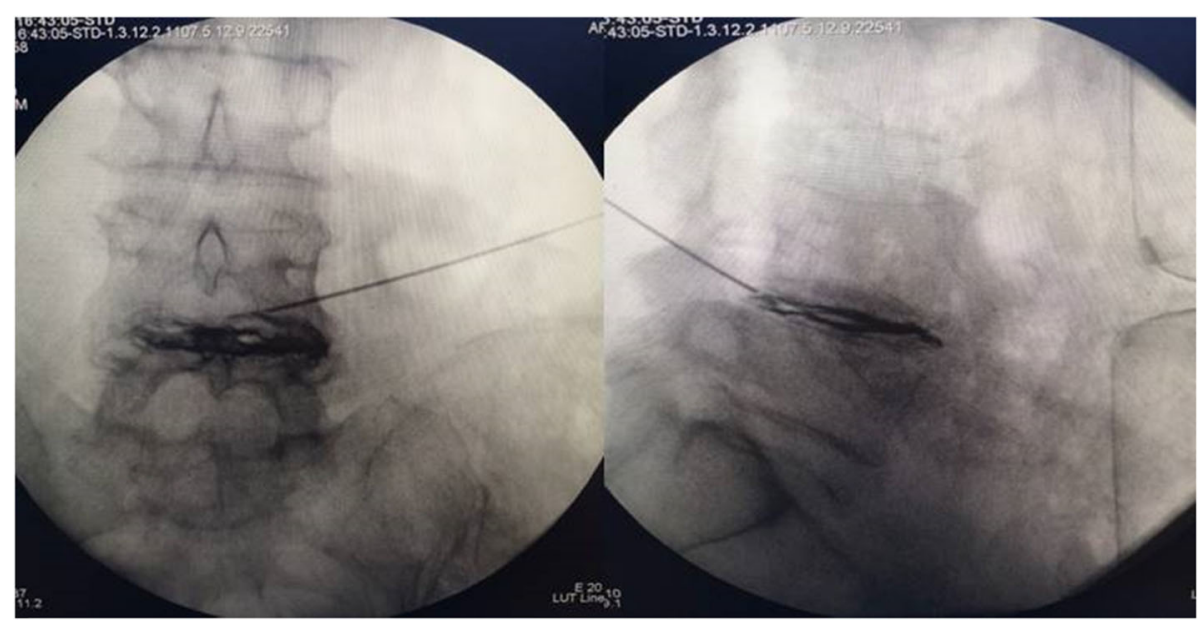

Fig. 3 Anteroposterior and lateral C-arm images with needle placement and dye spreading along the disc

more severe the disability. The Global perceived effect (GPE) scale is a 7-question scale that asks subjects to rate their condition after receiving treatment, where $1=$ worst ever and $7=$ best ever. Success was defined as a score $\geq 5$. Recurrent disc herniation is defined as a painless interval of at least 6 months after surgery, with herniated disc material at the same level and presenting the same symptoms as before surgery [12].

\section{Outcomes}

The primary outcomes were VAS and ODI preoperation, 1, 3, 6, 12, and 24 months after the operation. The secondary outcomes included operation time, hospitalization time, complication and recurrence.

\section{Statistical analysis}

The statistical analysis was performed with SPSS 24.0 for Windows (SPSS, Inc., IBM). Measured data were tested for normal distribution and the homogeneity of variance. Numeric variables were expressed as Mean \pm SD and analyzed by Independent-Samples T-test. Repeated measures of ANOVA (with Bonferroni confidence interval adjustment) tests were conducted for VAS and ODI. Categorical data were expressed by $\mathrm{N}(\%)$ and were analyzed with the $x^{2}$ test. The value of $p<0.05$ was taken as a significant difference.

Sensitivity analysis was performed to account for the patients who didn't receive open surgery during the 2year study period. The recorded value was excluded, as for the patients who underwent open surgery.

\section{Results}

\section{General information}

There was no significant difference in the sex, age, BMI, classification of disc herniation and hospitalization time between the two groups $(P>0.05)$. Treatment time in
Group TR (63.42 \pm 9.79$)$ was significantly longer than that in Group $\mathrm{T}(29.02 \pm 7.49)(P<0.001)$. The occurrence of recurrence rates in Group TR (34.17\%) was lower than that in Group T (54.55\%) $(P=0.002)$. During the 2-year follow-up, in Group T, 38 patients underwent open surgery; and in Group TR, 25 patients underwent open surgery. No severe complications, such as spinal injury and paraplegia, occurred in the patients in the three groups. In Group T, nerve root injury occurred in 2 patients. In Group TR, nerve root injury occurred in 4 patients, dural puncture occurred in 2 patients. The complications were reversible and resolved within 3 months. The complication rate during follow-up had no significant difference between the two groups $(P>0.05)$ (Table 1).

\section{Comparison of VAS}

There was no significant difference in the postoperative low back pain and lower limb radicular pain (VAS score) at the pre-operation between the two groups. The VAS of the low back pain and lower limb radicular pain at each observation point of the post-operation were significantly decreased compared with the pre-operation in both groups $(P<0.05)$. There was no statistical difference of VAS between the two groups at 1 and 3 months of the post-operation $(P>0.05)$. However, The VAS scores in Group TR were significantly lower than that in Group $\mathrm{T}$ at 6,12 and 24 months of the post-operation $(P<0.05)$.

\section{Comparison of ODI}

There was no significant difference in ODI score at the pre-operation between the two groups. The ODI of the low back pain and sciatica at each observation point of the post-operation were significantly decreased compared with the pre-operation in both groups $(P<0.05)$. 
Table 1 Comparison of general data between Group T and Group TR

\begin{tabular}{|c|c|c|c|c|c|}
\hline & & Group T $(n=110)$ & Group TR $(n=120)$ & $t /\left(x^{2}\right)$ & $P$ \\
\hline Male/female & & $47 / 63$ & $53 / 67$ & $(0.048)$ & 0.826 \\
\hline Age (years) & & $64.70 \pm 14.23$ & $65.54 \pm 16.06$ & -0.419 & 0.675 \\
\hline BMI $\left(\mathrm{kg} / \mathrm{m}^{2}\right)$ & & $24.48 \pm 5.05$ & $24.43 \pm 5.20$ & 0.077 & 0.939 \\
\hline \multirow[t]{2}{*}{ Disc herniation classification } & Protrusion & 62 & 66 & $(0.043)$ & 0.835 \\
\hline & Extrusion & 48 & 54 & & \\
\hline Hospitalization time (days) & & $5.39 \pm 1.24$ & $5.88 \pm 2.43$ & -1.907 & 0.058 \\
\hline Operation time (min) & & $29.02 \pm 7.49$ & $63.42 \pm 9.79$ & -30.092 & $<0.001^{*}$ \\
\hline Complication & & $2(1.82 \%)$ & $6(5 \%)$ & $(0.913)$ & 0.339 \\
\hline Recurrence & & $60(54.55 \%)$ & $41(34.17 \%)$ & $(9.677)$ & $0.002^{*}$ \\
\hline
\end{tabular}

Notes: Numeric data were expressed as Mean \pm SD and analyzed by Independent-Samples T-test. Categorical data were expressed by the number of patients (\%) and were analyzed with the $X 2$ test. Group T: TFESI group; Group TR: TFESI combined with RF group. ${ }^{*} P<0.05$, Group T vs Group TR

Abbreviations: BMI body mass index, VAS visual analog scale, ODI Oswestry Disability Index, TFESI transforaminal epidural steroid injection, RF radio frequency

There was no statistical difference in ODI between the two groups at 1 and 3 months of the post-operation $(P>$ $0.05)$. However, The ODI scores in Group TR were significantly lower than that in Group $\mathrm{T}$ at 6,12 and 24 months of the post-operation $(P<0.05)$.

\section{Comparison of GPE}

The percentage of patients with GPE $\geq 5$ was shown in Table 2. The GPE in group A decreased with time; it was significantly lower at 6,12 and 24 months after treatment than that in group B $(P<0.05)$. The GPE in group $B$ was higher in the early days, while that at 3 months after treatment was significantly higher than group A $(P<0.05)$ (Table 2).

\section{Sensitivity analysis}

Patients who received open surgery during the 2-year study period were excluded. There was no significant difference in ODI score and VAS score at the preoperation between the two groups. The ODI of the low back pain and sciatica and the VAS of the low back pain and lower limb radicular pain at each observation point of the post-operation were significantly decreased compared with the pre-operation in both groups $(P<0.05)$. There was no statistical difference of ODI and VAS between the two groups at 1 and 3 months of the postoperation $(P>0.05)$. However, The ODI scores and VAS scores in Group TR were significantly lower than those in Group T at 6, 12 and 24 months of the post-operation $(\mathrm{P}<0.05)$. The results were similar to those without exclusion. (Tables 3 and 4).

\section{Discussion}

LDH is one of the most common causes of low back pain and sciatica, it affects the daily life of patients. Therefore, there is an urgent need to alleviate the pain and improve the quality of life of these patients.

The mechanism of pain caused by LDH is multifaceted, may be caused by mechanical and/or inflammatory factors. Disc herniation can cause direct compression of nerve roots or dorsal root ganglia, as well as indirect compression of perineural blood vessels. Once the epidural tissue around the nerve root and the nerve root itself get inflamed and produce a series of

Table 2 Comparison of GPE after treatment in the two groups ( $n, \%)$

\begin{tabular}{lllll}
\hline Time & Group & \multicolumn{1}{c}{$\boldsymbol{P}$} \\
\cline { 3 - 4 } & & T $(\boldsymbol{n}=\mathbf{1 1 0})$ & $98(81.7 \%)$ & 0.715 \\
\hline 1 month & & $88(80.0 \%)$ & $99(82.5 \%)$ & 0.042 \\
months & & $83(75.5 \%)$ & $91(75.8 \%)$ & 0.008 \\
12 months & & $78(70.9 \%)$ & $82(68.3 \%)$ & 0.015 \\
24 months & Total & $61(55.5 \%)$ & $76(63.3 \%)$ & 0.030 \\
& Without further surgery & $49(44.5 \%)$ & $56(58 \%) n=95$ & 0.013 \\
& After open surgery & $21(29 \%) n=72$ & $20(80 \%) n=25$ & 0.577 \\
\hline
\end{tabular}

Notes: GPE results: percentages of patients with score $\geq 5$. Data are presented as numbers (\%) of patients. Group T: TFESI; Group TR: TFESI combined with RF. Group T compared to Group TR, * $P<0.05$

Abbreviations: GPE global perceived effect, TFESI transforaminal epidural steroid injection, RF radio frequency 
Table 3 Comparison of VAS between Group T and Group TR without further surgery at different time

\begin{tabular}{|c|c|c|c|c|c|c|c|}
\hline \multirow[t]{2}{*}{ Group } & & \multirow{2}{*}{$\begin{array}{l}\text { Pre- } \\
\text { operation }\end{array}$} & \multicolumn{5}{|c|}{ Post-operation } \\
\hline & & & 1 month & 3 months & 6 months & 12 months & 24 months \\
\hline \multirow[t]{2}{*}{ Group T $(n=72)$} & low back pain & $7.04 \pm 1.02$ & $2.10 \pm 0.96^{\mathrm{a}}$ & $2.38 \pm 0.97^{a}$ & $2.66 \pm 1.07^{\mathrm{a}}$ & $3.27 \pm 1.02^{\mathrm{a}}$ & $3.33 \pm 0.93^{\mathrm{a}}$ \\
\hline & sciatica & $7.59 \pm 1.01$ & $2.10 \pm 0.99^{\mathrm{a}}$ & $2.37 \pm 0.96^{\mathrm{a}}$ & $2.67 \pm 1.07^{\mathrm{a}}$ & $3.21 \pm 0.96^{\mathrm{a}}$ & $3.14 \pm 0.89^{\mathrm{a}}$ \\
\hline \multirow[t]{2}{*}{ Group TR $(n=95)$} & low back pain & $7.12 \pm 0.98$ & $2.16 \pm 0.87^{a}$ & $2.01 \pm 0.90^{\mathrm{a}}$ & $1.96 \pm 0.78^{\mathrm{ab}}$ & $2.20 \pm 0.91^{\mathrm{ab}}$ & $2.13 \pm 0.72^{\mathrm{ab}}$ \\
\hline & sciatica & $7.52 \pm 1.04$ & $2.15 \pm 0.87^{a}$ & $2.10 \pm 0.91^{a}$ & $1.98 \pm 0.79^{\mathrm{ab}}$ & $2.17 \pm 0.91^{\mathrm{ab}}$ & $2.38 \pm 0.71^{\mathrm{ab}}$ \\
\hline \multirow[t]{2}{*}{ Time $F, P$} & low back pain & $661.957,<0.001$ & & & & & \\
\hline & sciatica & $666.713,<0.001$ & & & & & \\
\hline \multirow[t]{2}{*}{ Group F, P } & low back pain & $30.212,<0.001$ & & & & & \\
\hline & sciatica & $30.356,<0.001$ & & & & & \\
\hline \multirow[t]{2}{*}{ Time * Group F, P } & low back pain & $18.496,=0.001$ & & & & & \\
\hline & sciatica & $14.635,<0.001$ & & & & & \\
\hline
\end{tabular}

Notes: Patients who received open surgery during the 2-year study period were deleted. Data are presented as mean \pm SD. The groups were compared by repeated measures analysis of variance (ANOVA). Bonferroni correction was used to correct multiple comparisons. Group T: TFESI group; Group TF: TFESI combined with RF group; vs pre-operation in the same group, ${ }^{\mathrm{a}} P<0.05$; vs Group T in the same time, ${ }^{\mathrm{b}} P<0.05$

Abbreviations: VAS visual analog scale, TFESI transforaminal epidural steroid injection, RF radio frequency

inflammatory mediators, all of these mediators activate the afferent nerves, and make the nerves very sensitive to pressure and cause pain [13-16]. Currently, most $\mathrm{LDH}$ are treated by reducing stress and/or reducing the release of inflammatory factors. With the continuous development of spinal surgery technology, interventional therapy is increasingly performed due to its many advantages over open surgery, including minimal tissue trauma, fewer surgical complications, and earlier postoperative recovery.

TFESI is usually performed in patients with LDH. The goal is to deliver the drug directly to the damaged spinal nerve root. The most common drug is to use a mixture of local anesthetics and corticosteroids. Corticosteroids can inhibit the production and release of proinflammatory materials. Local anesthetics can inhibit the generation of action potentials, nerve impulses in response to noxious stimuli, and the transmission of pain stimuli to the brain. Several previous studies have demonstrated excellent short-term outcomes of TFESI in patients with LDH. It may result in improvement in lumbosacral radicular pain between two and six weeks, which may relate to the duration of the therapeutic effect of corticosteroid $[17,18]$. Previous studies have reported that the short-term success rate is about $34-78 \%[19,20]$. However, many studies have shown controversial results about the long-term effects of the procedure [21, 22]. Pinto review analysis showed that epidural steroid injections have short-term effects on relieving low back pain and disability compared with placebo in patients with LDH but no effect in the long-term [23]. The present study showed that all patients had satisfactory clinical results six months after treatment in the two groups. In the TFESI group, we found some remarkable effects in the short term, but the long-term effect is not obvious, and the associated recurrence rate is higher than group $B$ in this study. We analyze the reason that may be related to the local nerve compression has not been relieved, and local inflammatory factors regroup.

RF has been applied for the herniated disc of lumbar or cervical [24]. Through an electrode, an alternating current (frequency, $250-500 \mathrm{kHz}$ ) is produced by a radio frequency generator, causing ionic movements in the tissue directly surrounding the active tip. Under the

Table 4 Comparison of ODI between Group T and Group TR without further surgery at different time

\begin{tabular}{|c|c|c|c|c|c|c|}
\hline \multirow[t]{2}{*}{ Group } & \multirow{2}{*}{$\begin{array}{l}\text { Pre- } \\
\text { operation }\end{array}$} & \multicolumn{5}{|c|}{ Post-operation } \\
\hline & & 1 month & 3 months & 6 months & 12 months & 24 months \\
\hline Group T $(n=72)$ & $69.45 \pm 6.71$ & $14.90 \pm 3.90^{\mathrm{a}}$ & $16.12 \pm 4.39^{a}$ & $26.12 \pm 6.05^{a}$ & $26.11 \pm 8.92^{\mathrm{a}}$ & $27.77 \pm 8.46^{a}$ \\
\hline Group TR $(n=95)$ & $70.76 \pm 6.68$ & $15.27 \pm 3.86^{a}$ & $15.54 \pm 5.37^{a}$ & $15.68 \pm 4.61^{a b}$ & $19.19 \pm 6.34^{a b}$ & $20.91 \pm 7.20^{a b}$ \\
\hline Time $F, P$ & $1825.276,<0.001$ & & & & & \\
\hline Group F, P & $94.292,<0.001$ & & & & & \\
\hline Time * Group F, P & $33.229,<0.001$ & & & & & \\
\hline
\end{tabular}

Notes: Patients who received open surgery during the 2-year study period were deleted. Data are presented as mean \pm SD. The groups were compared by repeated measures analysis of variance (ANOVA). Bonferroni correction was used to correct multiple comparisons. Group T: TFESI group; Group TF: TFESI combined with RF group; vs pre-operation in the same group, ${ }^{\mathrm{a}} P<0.05$; vs Group $\mathrm{T}$ in the same time, ${ }^{\mathrm{b}} P<0.05$ Abbreviations: ODI Oswestry Disability Index, TFESI transforaminal epidural steroid injection, RF radio frequency 
condition of high temperature, RF ablation disrupts the molecular chains in nucleus pulposus tissue, leading to collagen shrinkage, nucleus pulposus degeneration, coagulation, atrophy, and reduction of disc total volume. Therefore, the intradiscal pressure was decreased and the stimulation of the nerve root was reduced. At the same time, RF can increase the local temperature in a short time. The thermal effects can improve local blood circulation, easing the inflammatory reaction of the rupture of the intervertebral disc near the nerve roots and within the spinal canal [25]. Many studies have shown that the long-term results were satisfactory. Nie provides a retrospective evaluation follow up five years, which found that RF can reduce pain in patients with lumbar disc herniation and improve quality of life in a longterm [7]. Our results indicate that in group TR, the VAS and ODI scores improved significantly over a longer period. TFESI combined with RF showed fast onset and long maintenance time. We considered the reason as follows: local anesthetics and cortisol drugs can alleviate pain in the short term; RF decompresses nerve roots and improves the internal environment around nerve roots, thereby achieving a long-term Analgesic effect.

Our research has several limitations. Firstly, this was a retrospective study. Therefore, there may be inherent bias associated with patient selection and missing patient information. Secondly, the study was performed in only one hospital with limited patients enrolled, larger scale clinical trial with multiple centers is needed in the future.

\section{Conclusion}

The findings indicate that TFESI combined with RF for the treatment of LDH can effectively and rapidly relieve pain symptoms, improve quality of life, and have longterm satisfactory results but a $20 \%$ ratio of open surgery during follow-up must be anticipated.

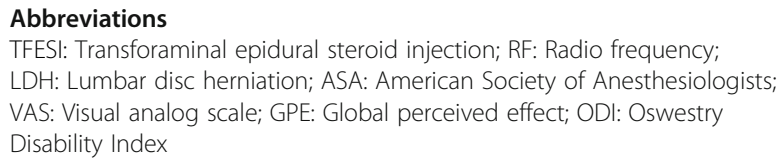

\section{Authors' contributions}

All authors participated in the interpretation of study results, and in the drafting, critical revision, and approval of the final version of the manuscript, and all authors agree to be accountable for all aspects of the work. WBW was in charge and contributed to all stages of the present study.; LW was responsible for participated in the design of the study, made revisions of the manuscript and approved the final version. WBW and SJD contributed to interpreting the data and writing the final manuscript; $T L$ and JW were contributors in writing and editing the manuscript. The author(s) read and approved the final manuscript.

\section{Funding}

This work was supported by the National Natural Science Foundation of China, shenzhen basic research center for robotics (No. U1913216). The funding bodies played no role in the design of the study and collection, analysis, and interpretation of data and in writing the manuscript.

\section{Availability of data and materials}

The authors will allow the sharing of participant data. The data will be available to anyone who wishes to access them for any purpose. The data will be accessible from immediately the following publication to 6 months after publication, and contact should be made via the first author by email.

\section{Declarations}

\section{Consent to publication}

Not applicable.

\section{Ethics approval and consent to participate}

This study was approved by the clinical research ethics committee of YangLing Demonstration Zone Hospital,ShaanXi,China (No. 2016-021). This study followed the Good Clinical Practice guidelines and the guidelines of the Helsinki Declaration. Written informed consent was obtained from all individual participants included in the study.

\section{Competing interests}

The authors report no conflicts of interest in this work

\section{Author details}

${ }^{1}$ The Key Laboratory of Biomedical Information Engineering of Ministry of Education, The Key Laboratory of Neuro-informatics \& Rehabilitation Engineering of Ministry of Civil Affairs, and Institute of Health and Rehabilitation Science, School of Life Science and Technology, Xi'an Jiaotong University, Xi'an 710049, P. R. China. ${ }^{2}$ National Engineering Research Center of Health Care and Medical Devices, Guangzhou, China. ${ }^{3}$ Department of orthopedics, Shaanxi Provincial people's Hospital, Xi'an, Shaanxi, China. ${ }^{4}$ Department of Anesthesia, Shaanxi Provincial Cancer Hospital, Xi'an, Shaanxi, China. ${ }^{5}$ Department of Pain, YangLing Demonstration Zone Hospital, Yangling, Shaanxi, China.

Received: 29 July 2020 Accepted: 31 March 2021

Published online: 12 April 2021

References

1. Ramakrishnan A, Webb KM, Cowperthwaite MC. One-year outcomes of early-crossover patients in a cohort receiving nonoperative care for lumbar disc herniation. J Neurosurg Spine. 2017;27(4):391-6. https://doi.org/10.31 71/2017.2.SPINE16760.

2. Lurie JD, Tosteson TD, Tosteson AN, Zhao W, Morgan TS, Abdu WA, et al. Surgical versus nonoperative treatment for lumbar disc herniation: eightyear results for the spine patient outcomes research trial. Spine (Phila Pa 1976). 2014;39(1):3-16. https://doi.org/10.1097/BRS.0000000000000088.

3. Tak HJ, Jones R, Cho YW, Kim EH, Ahn SH. Clinical evaluation of transforaminal epidural steroid injection in patients with gadolinium enhancing spinal nerves associated with disc herniation. Pain Physician. 2015;18(2):E177-85.

4. Kennedy DJ, Levin J, Rosenquist R, Singh V, Smith C, Stojanovic MP, et al. Epidural Steroid Injections are Safe and Effective: Multisociety Letter in Support of the Safety and Effectiveness of Epidural Steroid Injections. Pain medicine (Malden, Mass). 2015;16(5):833-8.

5. Maas E, Juch J, Huygen F. Radiofrequency denervation for chronic low Back pain-reply. Jama. 2017;318(22):2256-7. https://doi.org/10.1001/ja ma.2017.16390

6. Kim NH, Hong Y, Lee SH. Two-year clinical outcomes of radiofrequency focal ablation using a navigable plasma disc decompression device in patients with lumbar disc herniation: efficacy and complications. J Pain Res. 2018;11:2229-37. https://doi.org/10.2147/JPR.S170704.

7. Nie HY, Qi YB, Li N, Wang SL, Cao YX. Comprehensive comparison of therapeutic efficacy of radiofrequency target disc decompression and nucleoplasty for lumbar disc herniation: a five year follow-up. Int Orthop. 2018;42(4):843-9. https://doi.org/10.1007/s00264-017-3661-5. 
8. Fardon DF, Milette PC. Nomenclature and classification of lumbar disc pathology. Recommendations of the Combined task Forces of the North American Spine Society, American Society of Spine Radiology, and American Society of Neuroradiology. Spine (Phila Pa 1976). 2001;26(5):E93-E113.

9. Faiz KW: [VAS--visual analog scale]. Tidsskrift for den Norske laegeforening: tidsskrift for praktisk medicin, ny raekke 2014, 134(3):323.

10. Fairbank JC, Pynsent PB. The Oswestry disability index. Spine (Phila Pa 1976). 2000;25(22):2940-52; discussion 2952. https://doi.org/10.1097/00007632-2 00011150-00017.

11. Kamper SJ, Ostelo RW, Knol DL, Maher CG, de Vet HC, Hancock MJ. Global perceived effect scales provided reliable assessments of health transition in people with musculoskeletal disorders, but ratings are strongly influenced by current status. J Clin Epidemiol. 2010;63(7):760-6 e761. https://doi.org/1 0.1016/j.jclinepi.2009.09.009.

12. Swartz KR, Trost GR. Recurrent lumbar disc herniation. Neurosurg Focus. 2003;15(3):E10. https://doi.org/10.3171/foc.2003.15.3.10.

13. Buric J, Rigobello L, Hooper D. Five and ten year follow-up on intradiscal ozone injection for disc herniation. Int J Spine Surg. 2014;8. https://doi.org/1 $0.14444 / 1017$

14. Crockett MT, Moynagh M, Long N, Kilcoyne A, Dicker P, Synnott K, et al. Ozone-augmented percutaneous discectomy: a novel treatment option for refractory discogenic sciatica. Clin Radiol. 2014;69(12):1280-6. https://doi. org/10.1016/j.crad.2014.08.008.

15. Li B, Xu XX, Du Y, Yang HF, Li Y, Zhang Q, et al. CT-guided chemonucleolysis combined with psoas compartment block in lumbar disc herniation: a randomized controlled study. Pain medicine (Malden, Mass). 2014;15(9):1470-6

16. Murphy K, Muto M, Steppan J, Meaders T, Boxley C. Treatment of Contained Herniated Lumbar Discs With Ozone and Corticosteroid: A Pilot Clinical Study. Canadian Association of Radiologists journal = Journal l'Association canadienne des radiologistes. 2015;66(4):377-84.

17. Pfirrmann CW, Oberholzer PA, Zanetti M, Boos N, Trudell DJ, Resnick D, et al. Selective nerve root blocks for the treatment of sciatica: evaluation of injection site and effectiveness--a study with patients and cadavers. Radiology. 2001;221(3):704-11. https://doi.org/10.1148/radiol.2213001635.

18. Armon C, Argoff CE, Samuels J, Backonja MM. Assessment: use of epidural steroid injections to treat radicular lumbosacral pain: report of the therapeutics and technology assessment Subcommittee of the American Academy of neurology. Neurology. 2007:68(10):723-9.

19. Bui J, Bogduk N. A systematic review of the effectiveness of CT-guided, lumbar transforaminal injection of steroids. Pain medicine (Malden, Mass). 2013;14(12):1860-5.

20. Bhatia A, Flamer D, Shah PS, Cohen SP. Transforaminal epidural steroid injections for treating lumbosacral radicular pain from herniated intervertebral discs: a systematic review and meta-analysis. Anesth Analg. 2016;122(3):857-70. https://doi.org/10.1213/ANE.0000000000001155.

21. Shamliyan TA, Staal JB, Goldmann D, Sands-Lincoln M. Epidural steroid injections for radicular lumbosacral pain: a systematic review. Phys Med rehabil Clin North Am. 2014;25(2):471-89 e471-450.

22. Joswig H, Neff A, Ruppert C, Hildebrandt G, Stienen MN. The value of shortterm pain relief in predicting the Long-term outcome of lumbar Transforaminal epidural steroid injections. World Neurosurg. 2017;107:76471. https://doi.org/10.1016/j.wneu.2017.08.055.

23. Pinto RZ, Maher CG, Ferreira ML, Hancock M, Oliveira VC, McLachlan AJ, et al. Epidural corticosteroid injections in the management of sciatica: a systematic review and meta-analysis. Ann Intern Med. 2012;157(12):865-77. https://doi.org/10.7326/0003-4819-157-12-201212180-00564.

24. Van Zundert J, Patijn J, Kessels A, Lamé I, van Suijlekom H, van Kleef M. Pulsed radiofrequency adjacent to the cervical dorsal root ganglion in chronic cervical radicular pain: a double blind sham controlled randomized clinical trial. Pain. 2007;127(1-2):173-82. https://doi.org/10.1016/.jpain.2006. 09.002 .

25. Van Boxem K, Huntoon M, Van Zundert J, Patijn J, van Kleef M, Joosten EA. Pulsed radiofrequency: a review of the basic science as applied to the pathophysiology of radicular pain: a call for clinical translation. Reg Anesth Pain Med. 2014;39(2):149-59. https://doi.org/10.1097/AAP. 0000000000000063 .

\section{Publisher's Note}

Springer Nature remains neutral with regard to jurisdictional claims in published maps and institutional affiliations.

Ready to submit your research? Choose BMC and benefit from:

- fast, convenient online submission

- thorough peer review by experienced researchers in your field

- rapid publication on acceptance

- support for research data, including large and complex data types

- gold Open Access which fosters wider collaboration and increased citations

- maximum visibility for your research: over $100 \mathrm{M}$ website views per year

At BMC, research is always in progress.

Learn more biomedcentral.com/submissions 